\title{
R. Hoffmann: Handsurgery (handchirurgie), 3rd edition
}

\author{
Thieme, Stuttgart, 2009, 420 pp, ISBN 978-3-13-1024203-7, €70
}

\section{Leo Clodius}

Received: 15 January 2011 / Accepted: 15 January 2011 / Published online: 12 February 2011

(C) Springer-Verlag 2011

This flexible manual is the third edition of a classic which began 12 years ago; however, medicine and medical science advances constantly as does clinical experience. The author stresses that this text presents the actual knowledge at the time this text went into print. The second edition of this popular book was published 10 years ago. Now there are new chapters and many more explanatory illustrations. This also underlines the importance of the challenging and more and more self-reliant field of hand surgery.

The new chapters present minimally invasive and endoscopic techniques and arthroscopy of the wrist. The entire text, which consists of 413 pages, is reduced to the essential aspects of diagnosis and therapy. When necessary, high quality drawings, photographs, and X-rays illustrate the text. All pages are color-marked on their upper top corner. A black 8-mm square is for the patient's history and physical examination, for pre- and postoperative measurements. A blue square is for amputation injuries, fractures, luxations, and soft tissue injuries including thermal injuries, congenital anomalies, tumors, and rheumatoid arthritis. The red square marks and explains the multiple operative principles and possible approaches. A detailed index of 15 pages, black color-marked, will help the reader to find the searched information.

If the reader masters the German language, he will enjoy all the detailed help on this comprehensive hand surgery text. It is also very well presented.

L. Clodius $(\square)$

Zürich, Switzerland

e-mail: eurjplastsurg@juno.com 